\title{
Erratum to: Integrating technology into cognitive behavior therapy for adolescent depression: a pilot study
}

Kenneth A. Kobak ${ }^{1 *}$, James C. Mundt ${ }^{1}$ and Betsy Kennard ${ }^{2}$

\section{Erratum to: Ann Gen Psychiatry (2015) 14:37} DOI 10.1186/s12991-015-0077-8

Following publication of the original version [1] of the article in the Annals of General Psychiatry, it was brought to our attention that there was an error in Table 7 .
It should say 'week 12' above columns 2 and 3, instead of 'week 8'.

Table 7 Clinical outcome measures: CBT vs. TAU

\begin{tabular}{llllll}
\hline & $\begin{array}{l}\text { QIDS-A: mean } \\
\text { change }\end{array}$ & $\begin{array}{l}\text { CGI-S: percent } \\
\text { normal or borderline } \\
\text { depressed at week 12 }\end{array}$ & $\begin{array}{l}\text { CGI: percent rated } \\
\text { much or very much } \\
\text { improved at week 12 }\end{array}$ & $\begin{array}{l}\text { Therapeutic alliance } \\
\text { rating: patients }\end{array}$ & $\begin{array}{l}\text { Therapeutic alliance } \\
\text { rating: clinicians }\end{array}$ \\
\hline CBT & 6.09 & $51.4 \%$ & $71.4 \%$ & 62.8 & 65.3 \\
TAU & 5.73 & $46.7 \%$ & $60 \%$ & 60.02 & 58.4 \\
Diff & 0.35 & & & 2.8 & 6.9 \\
P & 0.753 & 0.825 & 0.332 & 0.03 & 0.001 \\
Effect size & 0.08 & 0.11 & 0.28 & 0.31 & 0.70 \\
$\begin{array}{l}\text { 95\% Confidence } \\
\text { interval, effect size }\end{array}$ & $-0.433,0.6436$ & $-0.289,0.852$ & $-0.0273,0.0306$ & $0.7002,0.3496$ \\
\hline
\end{tabular}

\section{Author details}

${ }^{1}$ Center for Telepsychology, 22 North Harwood, Madison, WI 53717, USA. 2 UT Southwestern Medical Center, 5323 Harry Hines Boulevard, Dallas, TX 75390, USA.

The online version of the original article can be found under doi:10.1186/s12991-015-0077-8.
Received: 9 December 2015 Accepted: 11 December 2015

Published online: 15 January 2016

\section{Reference \\ 1. Kobak, et al. Integrating technology into cognitive behavior therapy for adolescent depression: a pilot study. Ann Gen Psychiatry. 2015;14:37.}

\footnotetext{
*Correspondence: kkobak@telepsychology.net

${ }^{1}$ Center for Telepsychology, 22 North Harwood, Madison, WI 53717, USA

Full list of author information is available at the end of the article
} 